\title{
Gastrointestinal Stromal Tumors: Molecular Mechanisms and Targeted Therapies
}

\author{
Erinn Downs-Kelly and Brian P. Rubin \\ Departments of Anatomic and Molecular Pathology, Cleveland Clinic, 9500 Euclid Avenue, L25, Cleveland, OH 44195, USA \\ Correspondence should be addressed to Erinn Downs-Kelly, downske@ccf.org
}

Received 22 December 2010; Accepted 25 January 2011

Academic Editor: Hanlin L. Wang

Copyright ( $) 2011$ E. Downs-Kelly and B. P. Rubin. This is an open access article distributed under the Creative Commons Attribution License, which permits unrestricted use, distribution, and reproduction in any medium, provided the original work is properly cited.

\begin{abstract}
Gastrointestinal stromal tumors (GISTs) are the most common mesenchymal neoplasms of the gastrointestinal tract and are diverse not only in their clinical behavior but also in their histologic appearance. GISTs are insensitive to conventional sarcoma chemotherapy and radiation. However GISTs are sensitive to small-molecule tyrosine kinase inhibitors as $85-90 \%$ of GISTs have KIT or platelet-derived growth factor receptor alpha (PDGFRA) mutations, which drive tumorigenesis. This review will briefly touch on the clinicopathological features of GIST, while the majority of the review will focus on the clinical and treatment ramifications of KIT and PDGFRA mutations found in GIST.
\end{abstract}

\section{Background}

The last twenty years have seen great advances in the understanding of gastrointestinal stromal tumors (GISTs), from identifying their typical immunohistochemical phenotype and the molecular alterations that drive these tumors to the knowledge of their biologic potential and the use of effective tryosine kinase inhibitor targeted therapy. GISTs are the most common mesenchymal neoplasms of the gastrointestinal tract, and although insensitive to conventional sarcoma chemotherapy and radiation, they have shown dramatic clinical response to targeted kinase therapy. Activating mutations in KIT or platelet-derived growth factor receptor alpha (PDGFRA) have been identified in up to $80 \%$ and $10 \%$ of GISTs, respectively, and these mutually exclusive gain-offunction mutations play a fundamental role in GIST development by constitutively activating tyrosine kinase receptors [1-6]. Imatininib mesylate (ST1571; Gleevec, Novartis, East Hanover, NJ) is a selective tryosine kinase inhibitor that targets KIT and PDGFRA. The original indication was for the treatment of metastatic or unresectable GISTs with patients showing clinical responses in up to $80 \%$ of cases [7]; current FDA-approved labeling includes use in the adjuvant setting following complete gross resection of GISTs [8].
GISTs may occur anywhere in the gastrointestinal tract but are most common in the stomach and small bowel (roughly $60 \%$ and $30 \%$, resp.), while $10 \%$ arise in other parts of the gastrointestinal tract (esophagus, colon, and rectum), and a small percentage are extragastrointestinal, arising in the mesentery, omentum, retroperitoneum, or pelvis $[9,10]$. Once thought to represent smooth muscle neoplasms [11-13], GISTs are now known to share features with interstitial cells of Cajal (ICC), based on ultrastructure findings and immunophenotyping [14-19]. ICC are present within the interstitium of the muscularis propria throughout the gastrointestinal tract and serve a pacemaker function by generating and propagating electrical slow waves of depolarization, effectively coordinating peristalsis [16-18, $20,21]$. The current hypothesis is that GISTs arise from either the ICC or from a common progenitor stem cell [22].

GISTs are heterogenous, both from a clinical and morphologic stand point. Clinically, GISTs range from a small incidental finding that is entirely benign to a larger symptomatic neoplasm that may behave aggressively with metastatic potential. Regardless of their clinical diversity, GISTs share common genetic alterations. As mentioned above, mutually exclusive mutations in KIT or PDGFRA have been identified in up to $80 \%$ and $10 \%$ of GISTs, respectively [1-5]. These mutations have been detected in small, 
incidentally identified GISTs, suggesting that they occur as an early event in tumorigenesis [23, 24]. The majority of these mutations are somatic; however, germline mutations have been identified in rare families [25-30]. Approximately $5 \%-10 \%$ of GIST patients will lack mutations in either gene although KIT kinase activation is identified even in the absence of the mutation [2]. More recently, a primary V600E $B R A F$ mutation was found within $7 \%$ of adult GIST patients that lacked either KIT or PDGFRA mutations [31]. Morphologically, GISTs may be either spindle cell, epithelioid, or mixed spindle and epithelioid cell types [32]. Epithelioid and mixed cell type GISTs are most commonly encountered in the stomach compared to other gastrointestinal sites $[33,34]$. CD117 (KIT), the product of the KIT gene, has been identified as a sensitive immunohistochemical marker of GISTs from all sites and is expressed in up to $95 \%$ of GISTs with expression seen in wild-type tumors as well [35]. Approximately 5\% of GISTs do not express KIT [36, 37], and this subset of KIT-negative GISTs frequently contain a PDGFRA mutation [3]. Roughly $70 \%$ of GISTs will express CD34 [38, 39], 20\%-30\% are positive for smooth muscle actin, 5\% may express some positivity for $\mathrm{S} 100$ protein, and $1 \%-2 \%$ are positive for desmin or keratin $[14,32,35]$.

\section{KIT and PDGFRA}

KIT and PDGFRA reside on chromosome 4q12 [40] with both genes encoding homologous transmembrane glycoproteins $[41,42]$ that are members of a type III tyrosine kinase receptor family. These transmembrane proteins contain an extracellular/ligand binding domain (EC) with five immunoglobulin-like loops that function in ligand binding and dimerization. This EC domain is connected to a cytoplasmic domain by a transmembrane domain. The cytoplasmic domain is composed of a juxtamembrane (JM) domain and tyrosine kinase domain (TK1 and TK2) which contains an adenosine triphosphate binding site and a phosphotransferase region separated by a kinase insert [43]. The JM domain regulates KIT tyrosine kinase activity by inhibiting activity in the absence of KIT ligand [44].

In the normal state, KIT and PDGFRA bind their respective ligands (stem cell factor and platelet-derived growth factors), leading to the phosphorylation of signal transduction proteins that modulate cell proliferation and chemotaxis and inhibit apoptosis $[45,46]$. The signal transduction pathways involved include the mitogen-activated protein kinase (MAPK), phosphatidylinositol 3'kinase (PI3K), and Janus kinase/signal transducers and activators of transcription (JAK/STAT) pathways [47]. These intercellular signaling pathways play an important role in the development and maintenance of various cells including the interstitial cells of Cajal, mast cells, melanocytes, and hematopoietic stem cells $[15,48,49]$.

\section{Mutations as Drivers of Tumorigenesis in GISTs}

Primary mutations in KIT or PDGFRA are a driving force for tumorigenesis and are identified prior to exposure to a tyrosine kinase inhibitor, while secondary mutations develop during targeted treatment with a tyrosine kinase inhibitor and account for acquired inhibitor resistance. KIT or PDGFRA mutations may affect either the regulatory domain (EC or JM domains) or the enzymatic domain (TK1 and TK2) of the tyrosine kinase receptor [50]. Regardless of either a primary or secondary mutation, KIT and PDGFRA mutations seen within GISTs activate receptor tyrosine kinases, leading to constitutive phosphorylation and the subsequent continued activation of the downstream intercellular signaling cascade.

The oncogenic role of mutational activation of KIT or PDGFRA kinases has been supported by familial GIST syndromes and animal studies. Familial GIST syndromes may arise from germline mutations in exon 8 , exon 11, exon 13, and exon 17 of KIT and in exon 12 of PDGFRA [27, 28, 51-57]. All of these syndromes have a high penetrance with nearly every effected family member developing GISTs that are typically multiple $[26,28,51,52,55,57,58]$, while other clinical findings appear to be dependent on the domain mutated. For example, mastocytosis, urticaria pigmentosa, and diffuse hyperplasia of ICC with progression to distinct GISTs have been associated with mutations involving the JM domain of KIT [25, 27], while mutations that affect the kinase domain essentially lack mastocytosis and urticaria pigmentosa [28-30]. Transgenic mouse models have been developed with "knock-in" KIT mutations at either exon 11 or exon 13 wherein the mice develop ICC hyperplasia and GISTs $[59,60]$. These are similar to the mutations identified in human sporadic and familial GISTs and supports that KIT activation is central to the development of GISTs.

\section{Genotype-Phenotype Correlations}

Some important genotype-phenotype correlations have been identified in GISTs, not only pertaining to clinical behavior but also to the expected morphology and anatomic site of involvement for a given mutation. As mentioned previously, up to $80 \%$ of sporadic GISTs have mutations involving KIT $[1-3,6,23]$ with the majority (approximately 75\%) involving exon 11 of the KIT JM domain [44, 61-63] (Figure 1). The mutations cluster at either the $3^{\prime}$ or $5^{\prime}$ end of the exon. Mutations at the $5^{\prime}$ end most frequently include internal deletions $[2,64-68]$ and single nucleotide substitutions [2,64-68], while duplications most commonly involve the $3^{\prime}$ end [69]. Although less common, internal tandem duplication mutations have been identified at the $3^{\prime}$ end of exon 11; clinically, these patients typically have gastric GISTs that follow an indolent course [68]. In comparison, an aggressive clinical course with a higher risk of recurrence and shorter survival has been noted in patients whose GISTs harbor deletions involving exon 11 [70-72]. This deletion has been shown to be an independent adverse prognostic factor [71] and when compared with GISTs that have other exon 11 mutations or are wild type, a poor disease-free survival has been associated with exon 11 deletions that specifically involve codon 557 and 558 [73-75]. The second most common KIT mutation site has been identified within exon 9 (distal extracellular domain); 


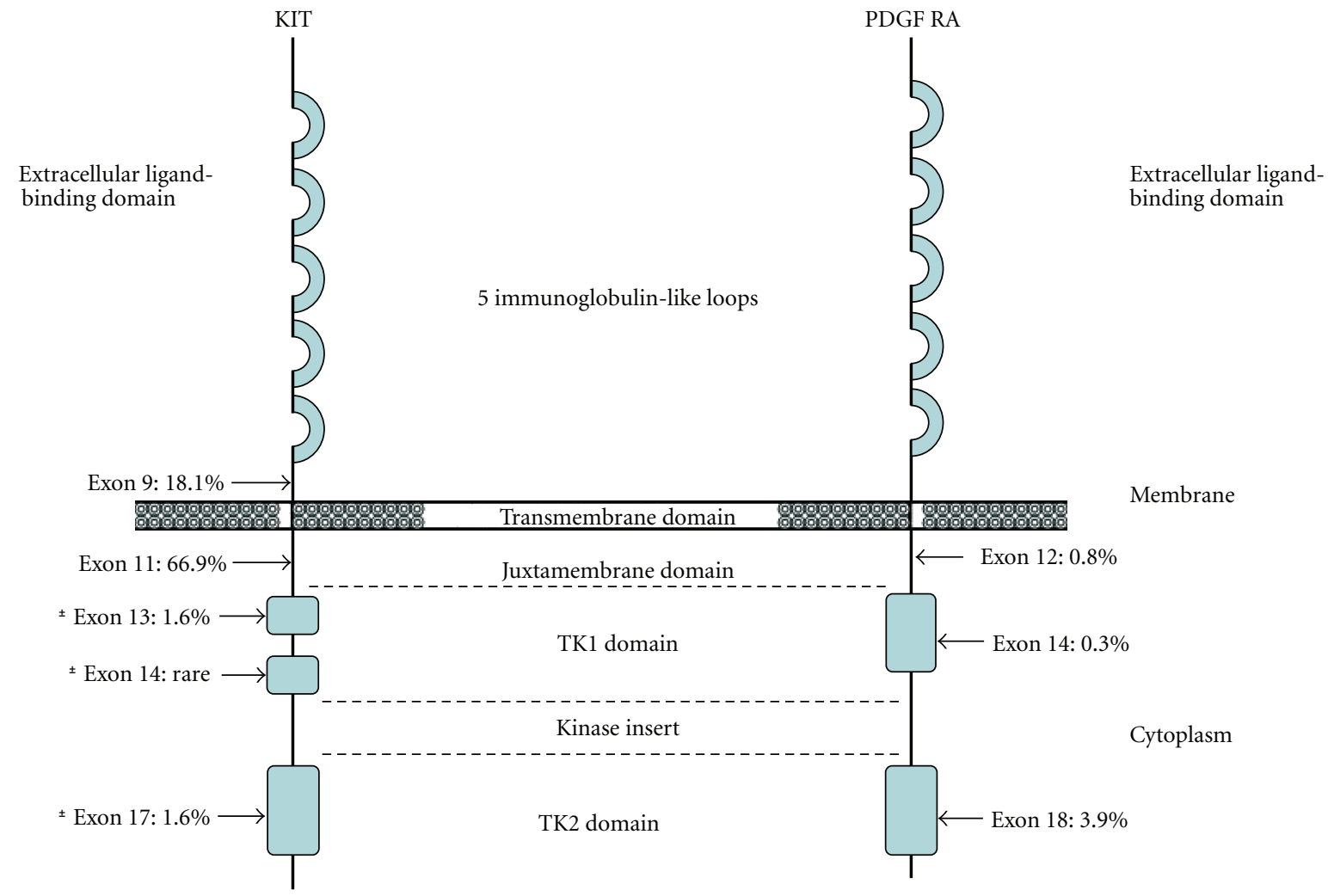

FIgURE 1: KIT and PDGFRA with locations and frequency of activating mutations in GISTs. Exons denoted with an * represent those most frequently involved by secondary mutations. Modified with permission from Heinrich et al. [3]. Copyright 2003 by the American Society of Clinical Oncology. All rights reserved.

in this site, duplications are most commonly found [6]. Exon 9 mutations have been identified in roughly 10\%$15 \%$ of sporadic GISTs and patients whose GISTs harbor this mutation commonly have small bowel involvement and a more clinically aggressive neoplasm $[68,75]$. Mutations in exons 13 and 17 affect the tyrosine kinase domain and are seen in less than $5 \%$ of sporadic GISTS $[6,76]$. Mutations involving these sites typically yield a spindle cell morphology and more frequent involvement of the small bowel than stomach [77].

Approximately $7 \%$ of GISTs harbor a mutation in PDGFRA [4, 5] with the majority being missense mutations identified in exon 18 affecting the TK2 domain [78, 79]. GISTs containing this mutation most commonly involve the stomach and have an epithelioid morphology [34, 78, 80]. PDGFRA exon 14 mutations are typically missense mutations that have been associated with epithelioid morphology, location within the stomach, and a favorable clinical course [78]. Rarely, mutations have been identified in the PDGFRA JM domain (exon 12), consisting predominately of point mutations, deletions, or deletion insertions $[4,78,79]$. In general, PDGFRA mutations are found within GISTs of the stomach and omentum, typically with epithelioid or mixed epithelioid/spindle cell morphology $[34,80-84]$.

\section{Treatment and Emergence of Secondary Mutations}

In regards to treatment, the main goal for a localized GIST is complete surgical resection with negative margins and preservation of an intact pseudocapsule. The tyrosine kinase inhibitor imatinib mesylate initially played a pivotal role in the management of metastatic or unresectable disease $[7,85-$ 87] and is now used in the adjuvant setting following complete gross resection [8]. Imatinib is a small molecule tyrosine kinase inhibitor whose structure mimics ATP and binds competitively to the intracellular portion of KIT, inhibiting signaling. This molecule also targets PDGFRA. The clinical response to imatinib has been shown to be correlative with the particular KIT or PDGFRA mutation present. GISTs with exon 11 KIT mutations have shown the best imatinib response rates (up to $80 \%$ of patients with advanced disease either had partial response or achieved stable disease), while tumours with no KIT mutation or those with a PDGFRA D842V mutation were less likely to have a favorable or a sustained response to imatinib [3, 88]. Other studies have suggested that patients with exon 9 KIT mutations may benefit from the use of higher dose imatinib $[89,90]$.

Most GIST patients will develop resistance to imatinib after initially achieving a clinical response. This resistance 
is typically via secondary mutations that involve the kinase domain of KIT with these additional mutations found on the same allele as the primary mutation [91-94]. Some of these secondary kinase domain mutations are imatinibresistant [91]. In these resistant tumours, the alternative kinase inhibitor sunitinib malate (SU11248 or Sutent, Pfizer, New York, NY) is being used [95-97]. This inhibitor targets several receptors including KIT, PDGFR, vascular endothelial growth factor receptors, and FLT3 and has shown clinical response in a variety of KIT and PDGFRA mutations; however, the development of sunitinib resistance is also an issue. Given this resistance, novel therapeutic strategies which target different aspects of intracellular signaling are being investigated. One strategy is to diminish KIT expression by inhibition of heat-shock protein (HSP)90, a chaperone protein that aids in protein folding to stabilize KIT from degradation. The inhibition of HSP90 prevents the stabilization of KIT and leads to its degradation $[98,99]$.

\section{Conclusions}

GISTs are clinically and histologically heterogenous neoplasms that are driven by oncogenic KIT or PDGFRA mutations. Although the majority of GISTs show an initial clinical response to imatinib, the development of resistance to this tyrosine kinase inhibitor as well as to the alternative kinase inhibitor sunitinib is problematic. Future strategies to overcome resistance will likely have to target other intracellular signaling pathways.

\section{References}

[1] S. Hirota, K. Isozaki, Y. Moriyama et al., "Gain-of-function mutations of c-kit in human gastrointestinal stromal tumors," Science, vol. 279, no. 5350, pp. 577-580, 1998.

[2] B. P. Rubin, S. Singer, C. Tsao et al., "KIT activation is a ubiquitous feature of gastrointestinal stromal tumors," Cancer Research, vol. 61, no. 22, pp. 8118-8121, 2001.

[3] M. C. Heinrich, C. L. Corless, G. D. Demetri et al., "Kinase mutations and imatinib response in patients with metastatic gastrointestinal stromal tumor," Journal of Clinical Oncology, vol. 21, no. 23, pp. 4342-4349, 2003.

[4] M. C. Heinrich, C. L. Corless, A. Duensing et al., "PDGFRA activating mutations in gastrointestinal stromal tumors," Science, vol. 299, no. 5607, pp. 708-710, 2003.

[5] S. Hirota, A. Ohashi, T. Nishida et al., "Gain-of-function mutations of platelet-derived growth factor receptor $\alpha$ gene in gastrointestinal stromal tumors," Gastroenterology, vol. 125, no. 3, pp. 660-667, 2003.

[6] M. L. Lux, B. P. Rubin, T. L. Biase et al., "KIT extracellular and kinase domain mutations in gastrointestinal stromal tumors," American Journal of Pathology, vol. 156, no. 3, pp. 791-795, 2000.

[7] G. D. Demetri, M. von Mehren, C. D. Blanke et al., "Efficacy and safety of imatinib mesylate in advanced gastrointestinal stromal tumors," New England Journal of Medicine, vol. 347, no. 7, pp. 472-480, 2002.

[8] R. P. DeMatteo, K. V. Ballman, C. R. Antonescu et al., "Adjuvant imatinib mesylate after resection of localised, primary gastrointestinal stromal tumour: a randomised, double-blind, placebo-controlled trial," Lancet, vol. 373, no. 9669, pp. 10971104, 2009.

[9] M. Miettinen, J. M. Monihan, M. Sarlomo-Rikala et al., "Gastrointestinal stromal tumors/smooth muscle tumors (GISTs) primary in the omentum and mesentery: clinicopathologic and immunohistochemical study of 26 cases," American Journal of Surgical Pathology, vol. 23, no. 9, pp. 1109-1118, 1999.

[10] J. D. Reith, J. R. Goldblum, R. H. Lyles, and S. W. Weiss, "Extragastrointestinal (soft tissue) stromal tumors: an analysis of 48 cases with emphasis on histologic predictors of outcome," Modern Pathology, vol. 13, no. 5, pp. 577-585, 2000.

[11] T. Golden and A. P. Stout, "Smooth muscle tumors of the gastrointestinal tract and retroperitoneal tissues," Surgery Gynecology \& Obstetrics, vol. 73, pp. 784-810, 1941.

[12] H. L. Evans, "Smooth muscle tumors of the gastrointestinal tract. A study of 56 cases followed for a minimum of 10 years," Cancer, vol. 56, no. 9, pp. 2242-2250, 1985.

[13] H. D. Appelman, "Smooth muscle tumors of the gastrointestinal tract. What we know now that Stout didn't know," American Journal of Surgical Pathology, vol. 10, pp. 83-99, 1986.

[14] L. G. Kindblom, H. E. Remotti, F. Aldenborg, and J. M. MeisKindblom, "Gastrointestinal pacemaker cell tumor (GIPACT): gastrointestinal stromal tumors show phenotypic characteristics of the interstitial cells of Cajal," American Journal of Pathology, vol. 152, no. 5, pp. 1259-1269, 1998.

[15] J. D. Huizinga, L. Thuneberg, M. Kluppel, J. Malysz, H. B. Mikkelsen, and A. Bernstein, "W/kit gene required for interstitial cells of Cajal and for intestinal pacemaker activity," Nature, vol. 373, no. 6512, pp. 347-349, 1995.

[16] M. Klüppel, J. D. Huizinga, J. Malysz, and A. Bernstein, "Developmental origin and Kit-dependent development of the interstitial cells of Cajal in the mammalian small intestine," Developmental Dynamics, vol. 211, no. 1, pp. 60-71, 1998.

[17] K. M. Sanders, "A case for interstitial cells of Cajal as pacemakers and mediators of neurotransmission in the gastrointestinal tract," Gastroenterology, vol. 111, no. 2, pp. 492-515, 1996.

[18] L. Thuneberg, "Interstitial cells of Cajal: intestinal pacemaker cells?" Advances in Anatomy, Embryology, and Cell Biology, vol. 71, pp. 1-130, 1982.

[19] J. K. Chan, "Mesenchymal tumors of the gastrointestinal tract: a paradise for acronyms (STUMP, GIST, GANT, and now GIPACT), implication of c-kit in genesis, and yet another of the many emerging roles of the interstitial cell of Cajal in the pathogenesis of gastrointestinal diseases?" Advances in Anatomic Pathology, vol. 6, no. 1, pp. 19-40, 1999.

[20] J. C. F. Lee, L. Thuneberg, I. Berezin, and J. D. Huizinga, "Generation of slow waves in membrane potential is an intrinsic property of interstitial cells of Cajal," American Journal of Physiology, vol. 277, no. 2, part 1, pp. G409-G423, 1999.

[21] J. J. Rumessen and L. Thuneberg, "Interstitial cells of Cajal in human small intestine: ultrastructural identification and organization between the main smooth muscle layers," Gastroenterology, vol. 100, no. 5, part 1, pp. 1417-1431, 1991.

[22] M. Miettinen, M. Sarlomo-Rikala, and J. Lasota, "Gastrointestinal stromal tumors: recent advances in understanding of their biology," Human Pathology, vol. 30, no. 10, pp. 12131220, 1999. 
[23] C. L. Corless, L. McGreevey, A. Haley, A. Town, and M. C. Heinrich, "KIT mutations are common in incidental gastrointestinal stromal tumors one centimeter or less in size," American Journal of Pathology, vol. 160, no. 5, pp. 1567-1572, 2002.

[24] A. Agaimy, P. H. Wünsch, F. Hofstaedter et al., "Minute Gastric Sclerosing Stromal Tumors (GIST Tumorlets) are common in adults and frequently show c-KIT mutations," American Journal of Surgical Pathology, vol. 31, no. 1, pp. 113-120, 2007.

[25] C. L. Corless, J. A. Fletcher, and M. C. Heinrich, "Biology of gastrointestinal stromal tumors," Journal of Clinical Oncology, vol. 22, no. 18, pp. 3813-3825, 2004.

[26] T. Nishida, S. Hirota, M. Taniguchi et al., "Familial gastrointestinal stromal tumours with germline mutation of the KIT gene," Nature Genetics, vol. 19, no. 4, pp. 323-324, 1998.

[27] M. Carballo, I. Roig, F. Aguilar et al., "Novel c-KIT germline mutation in a family with gastrointestinal stromal tumors and cutaneous hyperpigmentation," American Journal of Medical Genetics, vol. 132, no. 4, pp. 361-364, 2005.

[28] F. P. Li, J. A. Fletcher, M. C. Heinrich et al., "Familial gastrointestinal stromal tumor syndrome: phenotypic and molecular features in a kindred," Journal of Clinical Oncology, vol. 23, no. 12, pp. 2735-2743, 2005.

[29] C. O’Riain, C. L. Corless, M. C. Heinrich et al., “Gastrointestinal stromal tumors: insights from a new familial GIST kindred with unusual genetic and pathologic features," American Journal of Surgical Pathology, vol. 29, no. 12, pp. 1680-1683, 2005.

[30] K. Hartmann, E. Wardelmann, Y. Ma et al., "Novel germline mutation of KIT associated with familial gastrointestinal stromal tumors and mastocytosis," Gastroenterology, vol. 129, no. 3, pp. 1042-1046, 2005.

[31] N. P. Agaram, G. C. Wong, T. Guo et al., "Novel V600E BRAF mutations in imatinib-naive and imatinib-resistant gastrointestinal stromal tumors," Genes Chromosomes and Cancer, vol. 47, no. 10, pp. 853-859, 2008.

[32] C. D. M. Fletcher, J. J. Berman, C. Corless et al., "Diagnosis of gastrointestinal stromal tumors: a consensus approach," Human Pathology, vol. 33, no. 5, pp. 459-465, 2002.

[33] M. Miettinen, L. H. Sobin, and J. Lasota, "Gastrointestinal stromal tumors of the stomach: a clinicopathologic, immunohistochemical, and molecular genetic study of 1765 cases with long-term follow-up," American Journal of Surgical Pathology, vol. 29, no. 1, pp. 52-68, 2005.

[34] B. Wasag, M. Debiec-Rychter, P. Pauwels et al., "Differential expression of KIT/PDGFRA mutant isoforms in epithelioid and mixed variants of gastrointestinal stromal tumors depends predominantly on the tumor site," Modern Pathology, vol. 17, no. 8, pp. 889-894, 2004.

[35] M. Sarlomo-Rikala, A. J. Kovatich, A. Barusevicius, and M. Miettinen, "CD117: a sensitive marker for gastrointestinal stromal tumors that is more specific than CD34," Modern Pathology, vol. 11, no. 8, pp. 728-734, 1998.

[36] F. Medeiros, C. L. Corless, A. Duensing et al., "KIT-negative gastrointestinal stromal tumors: proof of concept and therapeutic implications," American Journal of Surgical Pathology, vol. 28, no. 7, pp. 889-894, 2004.

[37] M. Debiec-Rychter, B. Wasag, M. Stul et al., "Gastrointestinal stromal tumours (GISTs) negative for KIT (CD117 antigen) immunoreactivity," Journal of Pathology, vol. 202, no. 4, pp. 430-438, 2004.

[38] M. van de Rijn, M. R. Hendrickson, and R. V. Rouse, "CD34 expression by gastrointestinal tract stromal tumors," Human Pathology, vol. 25, no. 8, pp. 766-771, 1994.
[39] M. Miettinen, M. Virolainen, and R. Maarit-Sarlomo, "Gastrointestinal stromal tumors-value of CD34 antigen in their identification and separation from true leiomyomas and schwannomas," American Journal of Surgical Pathology, vol. 19, no. 2, pp. 207-216, 1995.

[40] G. Stenman, A. Eriksson, and L. Claesson-Welsh, "Human PDGFA receptor gene maps to the same region on chromosome 4 as the KIT oncogene," Genes Chromosomes and Cancer, vol. 1, no. 2, pp. 155-158, 1989.

[41] P. Besmer, J. E. Murphy, P. C. George et al., "A new acute transforming feline retrovirus and relationship of its oncogene v-kit with the protein kinase gene family," Nature, vol. 320, no. 6061, pp. 415-421, 1986.

[42] T. Matsui, M. Heidaran, T. Miki et al., "Isolation of a novel receptor cDNA establishes the existence of two PDGF receptor genes," Science, vol. 243, no. 4892, pp. 800-804, 1989.

[43] T. Pawson, "Regulation and targets of receptor tyrosine kinases," European Journal of Cancer, vol. 38, pp. S3-S10, 2002.

[44] C. D. Mol, D. R. Dougan, T. R. Schneider et al., "Structural basis for the autoinhibition and STI-571 inhibition of c-Kit tyrosine kinase," Journal of Biological Chemistry, vol. 279, no. 30, pp. 31655-31663, 2004.

[45] L. Rönnstrand, "Signal transduction via the stem cell factor receptor/c-Kit," Cellular and Molecular Life Sciences, vol. 61, no. 19-20, pp. 2535-2548, 2004.

[46] P. Blume-Jensen, L. Claesson-Welsh, A. Siegbahn, K. M. Zsebo, and B. C. H. Westermark Heldin, "Activation of the human ckit product by ligand-induced dimerization mediates circular actin reorganization and chemotaxis," EMBO Journal, vol. 10, no. 13, pp. 4121-4128, 1991.

[47] A. Duensing, F. Medeiros, B. McConarty et al., "Mechanisms of oncogenic KIT signal transduction in primary gastrointestinal stromal tumors (GISTs)," Oncogene, vol. 23, no. 22, pp. 3999-4006, 2004.

[48] S. Nishikawa, M. Kusakabe, K. Yoshinaga et al., "In utero manipulation of coat color formation by a monoclonal antic-kit antibody: two distinct waves of c-kit-dependency during melanocyte development," EMBO Journal, vol. 10, no. 8, pp. 2111-2118, 1991.

[49] H. Maeda, A. Yamagata, S. Nishlkawa et al., "Requirement of c-kit for development of intestinal pacemaker system," Development, vol. 116, no. 2, pp. 369-375, 1992.

[50] B. J. Longley, M. J. Reguera, and Y. Ma, "Classes of c-KIT activating mutations: proposed mechanisms of action and implications for disease classification and therapy," Leukemia Research, vol. 25, no. 7, pp. 571-576, 2001.

[51] H. Maeyama, E. Hidaka, H. Ota et al., "Familial gastrointestinal stromal tumor with hyperpigmentation: association with a germline mutation of the c-kit gene," Gastroenterology, vol. 120, no. 1, pp. 210-215, 2001.

[52] K. Isozaki, B. Terris, J. Belghiti, S. Schiffmann, S. Hirota, and J. M. Vanderwinden, "Germline-activating mutation in the kinase domain of KIT gene in familial gastrointestinal stromal tumors," American Journal of Pathology, vol. 157, no. 5, pp. 1581-1585, 2000.

[53] A. Beghini, M. Tibiletti, G. Roversi et al., "Germline mutation in the juxtamembrane domain of the kit gene in a family with gastrointestinal stromal tumors and urticaria pigmentosa," Cancer, vol. 92, no. 3, pp. 657-662, 2001.

[54] A. Chompret, C. Kannengiesser, M. Barrois et al., "PDGFRA germline mutation in a family with multiple cases of gastrointestinal stromal tumor," Gastroenterology, vol. 126, no. 1, pp. 318-321, 2004. 
[55] S. Hirota, T. Okazaki, Y. Kitamura, P. O’Brien, L. Kapusta, and I. Dardick, "Cause of familial and multiple gastrointestinal autonomic nerve tumors with hyperplasia of interstitial cells of Cajal is germline mutation of the c-kit gene," American Journal of Surgical Pathology, vol. 24, no. 2, pp. 326-327, 2000.

[56] J. Lasota and M. Miettinen, "A new familial GIST identified," American Journal of Surgical Pathology, vol. 30, no. 10, article 1342, 2006.

[57] S. Hirota, T. Nishida, K. Isozaki et al., "Familial gastrointestinal stromal tumors associated with dysphagia and novel type germline mutation of KIT gene," Gastroenterology, vol. 122, no. 5, pp. 1493-1499, 2002.

[58] P. O’Brien, L. Kapusta, I. Dardick, J. Axler, and A. Gnidec, "Multiple familial gastrointestinal autonomic nerve tumors and small intestinal neuronal dysplasia," American Journal of Surgical Pathology, vol. 23, no. 2, pp. 198-204, 1999.

[59] G. Sommer, V. Agosti, I. Ehlers et al., "Gastrointestinal stromal tumors in a mouse model by targeted mutation of the Kit receptor tyrosine kinase," Proceedings of the National Academy of Sciences of the United States of America, vol. 100, no. 11, pp. 6706-6711, 2003.

[60] B. P. Rubin, C. R. Antonescu, J. P. Scott-Browne et al., "A knock-in mouse model of gastrointestinal stromal tumor harboring Kit K641E," Cancer Research, vol. 65, no. 15, pp. 6631-6639, 2005.

[61] P. M. Chan, S. Ilangumaran, J. La Rose, A. Chakrabartty, and R. Rottapel, "Autoinhibition of the Kit receptor tyrosine kinase by the cytosolic juxtamembrane region," Molecular and Cellular Biology, vol. 23, no. 9, pp. 3067-3078, 2003.

[62] H. Kitayama, Y. Kanakura, T. Furitsu et al., "Constitutively activating mutations of c-kit receptor tyrosine kinase confer factor-independent growth and tumorigenicity of factordependent hematopoietic cell lines," Blood, vol. 85, no. 3, pp. 790-798, 1995.

[63] Y. Ma, M. E. Cunningham, X. Wang, I. Ghosh, L. Regan, and B. J. Longley, "Inhibition of spontaneous receptor phosphorylation by residues in a putative $\alpha$-helix in the KIT intracellular juxtamembrane region," Journal of Biological Chemistry, vol. 274, no. 19, pp. 13399-13402, 1999.

[64] J. Lasota, M. Jasinski, M. Sarlomo-Rikala, and M. Miettinen, "Mutations in exon 11 of c-kit occur preferentially in malignant versus benign gastrointestinal stromal tumors and do not occur in leiomyomas or leiomyosarcomas," American Journal of Pathology, vol. 154, no. 1, pp. 53-60, 1999.

[65] M. Taniguchi, T. Nishida, S. Hirota et al., "Effect of c-kit mutation on prognosis of gastrointestinal stromal tumors," Cancer Research, vol. 59, no. 17, pp. 4297-4300, 1999.

[66] S. Sakurai, T. Fukasawa, J. M. Chong, A. Tanaka, and M. Fukayama, "C-kit gene abnormalities in gastrointestinal stromal tumors (tumors of interstitial cells of cajal)," Japanese Journal of Cancer Research, vol. 90, no. 12, pp. 1321-1328, 1999.

[67] E. Wardelmann, I. Neidt, E. Bierhoff et al., "c-kit mutations in gastrointestinal stromal tumors occur preferentially in the spindle rather than in the epithelioid cell variant," Modern Pathology, vol. 15, no. 2, pp. 125-136, 2002.

[68] C. R. Antonescu, G. Sommer, L. Sarran et al., "Association of KIT exon 9 mutations with nongastric primary site and aggressive behavior: KIT mutation analysis and clinical correlates of 120 gastrointestinal stromal tumors," Clinical Cancer Research, vol. 9, no. 9, pp. 3329-3337, 2003.

[69] C. A. Moskaluk, Q. Tian, C. R. Marshall, C. A. Rumpel, D. W. Franquemont, and H. F. Frierson, "Mutations of c-kit JM domain are found in a minoritry of human gastrointestinal stromal tumors," Oncogene, vol. 18, no. 10, pp. 1897-1902, 1999.

[70] S. E. Steigen, T. J. Eide, B. Wasag, J. Lasota, and M. Miettinen, "Mutations in gastrointestinal stromal tumors-a populationbased study from northern Norway," APMIS, vol. 115, no. 4, pp. 289-298, 2007.

[71] J. Andersson, P. Bümming, J. M. Meis-Kindblom et al., "Gastrointestinal stromal tumors with KIT exon 11 deletions are associated with poor prognosis," Gastroenterology, vol. 130, no. 6, pp. 1573-1581, 2006.

[72] S. Cho, Y. Kitadai, S. Yoshida et al., "Deletion of the KIT gene is associated with liver metastasis and poor prognosis in patients with gastrointestinal stromal tumor in the stomach," International Journal of Oncology, vol. 28, no. 6, pp. 13611367, 2006.

[73] E. Wardelmann, I. Losen, V. Hans et al., "Deletion of Trp557 and Lys-558 in the juxtamembrane domain of the ckit protooncogene is associated with metastatic behavior of gastrointestinal stromal tumors," International Journal of Cancer, vol. 106, no. 6, pp. 887-895, 2003.

[74] J. Martín, A. Poveda, A. Llombart-Bosch et al., "Deletions affecting codons 557-558 of the c-KIT gene indicate a poor prognosis in patients with completely resected gastrointestinal stromal tumors: a study by the Spanish Group for Sarcoma Research (GEIS)," Journal of Clinical Oncology, vol. 23, no. 25, pp. 6190-6198, 2005.

[75] R. P. DeMatteo, J. S. Gold, L. Saran et al., "Tumor mitotic rate, size, and location independently predict recurrence after resection of primary gastrointestinal stromal tumor (GIST)," Cancer, vol. 112, no. 3, pp. 608-615, 2008.

[76] J. Lasota, A. Wozniak, M. Sarlomo-Rikala et al., "Mutations in exons 9 and 13 of KIT gene are rare events in gastrointestinal stromal tumors: a study of 200 cases," American Journal of Pathology, vol. 157, no. 4, pp. 1091-1095, 2000.

[77] J. Lasota, C. L. Corless, M. C. Heinrich et al., "Clinicopathologic profile of gastrointestinal stromal tumors (GISTs) with primary KIT exon 13 or exon 17 mutations: a multicenter study on 54 cases," Modern Pathology, vol. 21, no. 4, pp. 476484, 2008.

[78] J. Lasota, A. Dansonka-Mieszkowska, L. H. Sobin, and M. Miettinen, "A great majority of GISTs with PDGFRA mutations represent gastric tumors of low or no malignant potential," Laboratory Investigation, vol. 84, no. 7, pp. 874-883, 2004.

[79] C. L. Corless, A. Schroeder, D. Griffith et al., "PDGFRA mutations in gastrointestinal stromal tumors: frequency, spectrum and in vitro sensitivity to imatinib," Journal of Clinical Oncology, vol. 23, no. 23, pp. 5357-5364, 2005.

[80] E. Wardelmann, A. Hrychyk, S. Merkelbach-Bruse et al., "Association of platelet-derived growth factor receptor $\alpha$ mutations with gastric primary site and epithelioid or mixed cell morphology in gastrointestinal stromal tumors," Journal of Molecular Diagnostics, vol. 6, no. 3, pp. 197-204, 2004.

[81] J. Lasota, A. Dansonka-Mieszkowska, T. Stachura et al., "Gastrointestinal stromal tumors with internal tandem duplications in $3^{\prime}$ end of KIT juxtamembrane domain occur predominantly in stomach and generally seem to have a favorable course," Modern Pathology, vol. 16, no. 12, pp. 12571264, 2003.

[82] O. Daum, P. Grossmann, T. Vanecek, R. Sima, P. Mukensnabl, and M. Michal, "Diagnostic morphological features of PDGFRA-mutated gastrointestinal stromal tumors: molecular 
genetic and histologic analysis of 60 cases of gastric gastrointestinal stromal tumors," Annals of Diagnostic Pathology, vol. 11, no. 1, pp. 27-33, 2007.

[83] R. Penzel, S. Aulmann, M. Moock, M. Schwarzbach, R. J. Rieker, and G. Mechtersheimer, "The location of KIT and PDGFRA gene mutations in gastrointestinal stromal tumours is site and phenotype associated," Journal of Clinical Pathology, vol. 58, no. 6, pp. 634-639, 2005.

[84] S. Sakurai, T. Hasegawa, Y. Sakuma et al., "Myxoid epithelioid gastrointestinal stromal tumor (GIST) with mast cell infiltrations: a subtype of GIST with mutations of platelet-derived growth factor receptor alpha gene," Human Pathology, vol. 35, no. 10, pp. 1223-1230, 2004.

[85] C. D. Blanke, C. Rankin, G. D. Demetri et al., "Phase III randomized, intergroup trial assessing imatinib mesylate at two dose levels in patients with unresectable or metastatic gastrointestinal stromal tumors expressing the kit receptor tyrosine kinase: S0033," Journal of Clinical Oncology, vol. 26, no. 4, pp. 626-632, 2008.

[86] J. Verweij, P. G. Casali, J. Zalcberg et al., "Progression-free survival in gastrointestinal stromal tumours with high-dose imatinib: randomised trial," Lancet, vol. 364, no. 9440, pp. 1127-1134, 2004.

[87] C. D. Blanke, G. D. Demetri, M. von Mehren et al., "Long-term results from a randomized phase II trial of standard- versus higher-dose imatinib mesylate for patients with unresectable or metastatic gastrointestinal stromal tumors expressing KIT," Journal of Clinical Oncology, vol. 26, no. 4, pp. 620-625, 2008.

[88] M. Debiec-Rychter, H. Dumez, I. Judson et al., "Use of c-KIT/PDGFRA mutational analysis to predict the clinical response to imatinib in patients with advanced gastrointestinal stromal tumours entered on phase I and II studies of the EORTC Soft Tissue and Bone Sarcoma Group," European Journal of Cancer, vol. 40, no. 5, pp. 689-695, 2004.

[89] M. Debiec-Rychter, R. Sciot, A. Le Cesne et al., "KIT mutations and dose selection for imatinib in patients with advanced gastrointestinal stromal tumours," European Journal of Cancer, vol. 42, no. 8, pp. 1093-1103, 2006.

[90] M. C. Heinrich, K. Owzar, C. L. Corless et al., "Correlation of kinase genotype and clinical outcome in the North American intergroup phase III trial of imatinib mesylate for treatment of advanced gastrointestinal stromal tumor: CALGB 150105 study by cancer and leukemia group B and southwest oncology group," Journal of Clinical Oncology, vol. 26, no. 33, pp. 53605367, 2008.

[91] M. C. Heinrich, C. L. Corless, C. D. Blanke et al., "Molecular correlates of imatinib resistance in gastrointestinal stromal tumors," Journal of Clinical Oncology, vol. 24, no. 29, pp. 47644774, 2006.

[92] C. R. Antonescu, P. Besmer, T. Guo et al., "Acquired resistance to imatinib in gastrointestinal stromal tumor occurs through secondary gene mutation," Clinical Cancer Research, vol. 11, no. 11, pp. 4182-4190, 2005.

[93] L. L. Chen, J. C. Trent, E. F. Wu et al., "A missense mutation in KIT kinase domain 1 correlates with imatinib resistance in gastrointestinal stromal tumors," Cancer Research, vol. 64, no. 17, pp. 5913-5919, 2004.

[94] M. Debiec-Rychter, J. Cools, H. Dumez et al., "Mechanisms of resistance to imatinib mesylate in gastrointestinal stromal tumors and activity of the PKC412 inhibitor against imatinibresistant mutants," Gastroenterology, vol. 128, no. 2, pp. 270279, 2005.
[95] G. D. Demetri, A. T. van Oosterom, C. R. Garrett et al., "Efficacy and safety of sunitinib in patients with advanced gastrointestinal stromal tumour after failure of imatinib: a randomised controlled trial," Lancet, vol. 368, no. 9544, pp. 1329-1338, 2006.

[96] S. Faivre, C. Delbaldo, K. Vera et al., "Safety, pharmacokinetic, and antitumor activity of SU11248, a novel oral multitarget tyrosine kinase inhibitor, in patients with cancer," Journal of Clinical Oncology, vol. 24, no. 1, pp. 25-35, 2006.

[97] H. Joensuu, "Second line therapies for the treatment of gastrointestinal stromal tumor," Current Opinion in Oncology, vol. 19, no. 4, pp. 353-358, 2007.

[98] M. von Mehren, "Beyond imatinib: second generation c-KIT inhibitors for the management of gastrointestinal stromal tumors," Clinical Colorectal Cancer, vol. 6, pp. S30-34, 2006.

[99] S. Bauer, L. K. Yu, G. D. Demetri, and J. A. Fletcher, "Heat shock protein 90 inhibition in imatinib-resistant gastrointestinal stromal tumor," Cancer Research, vol. 66, no. 18, pp. 91539161, 2006. 


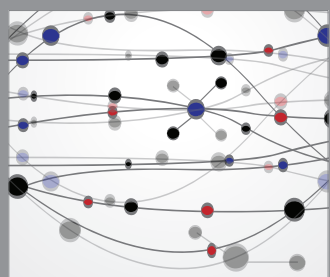

The Scientific World Journal
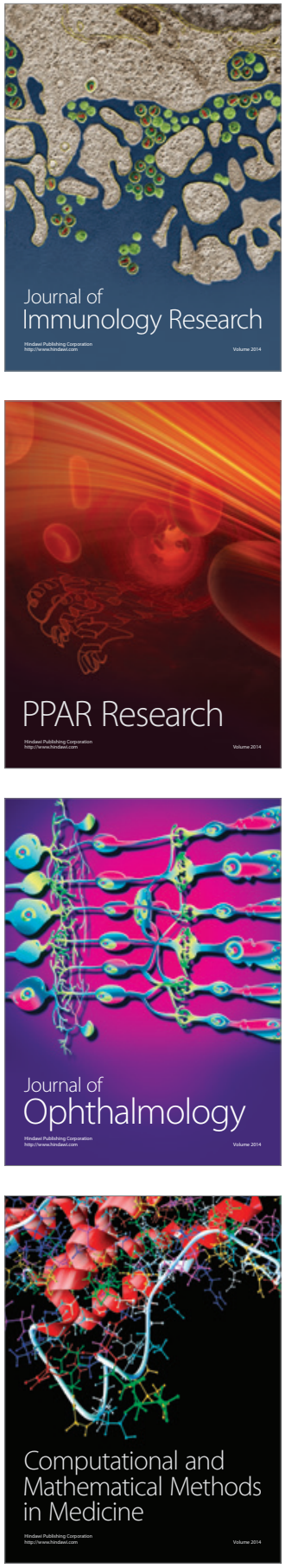

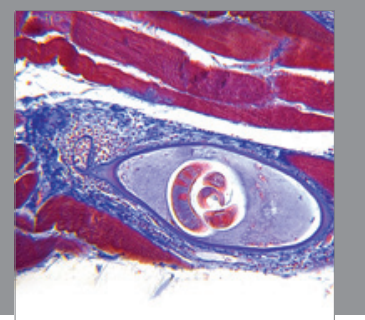

Gastroenterology

Research and Practice
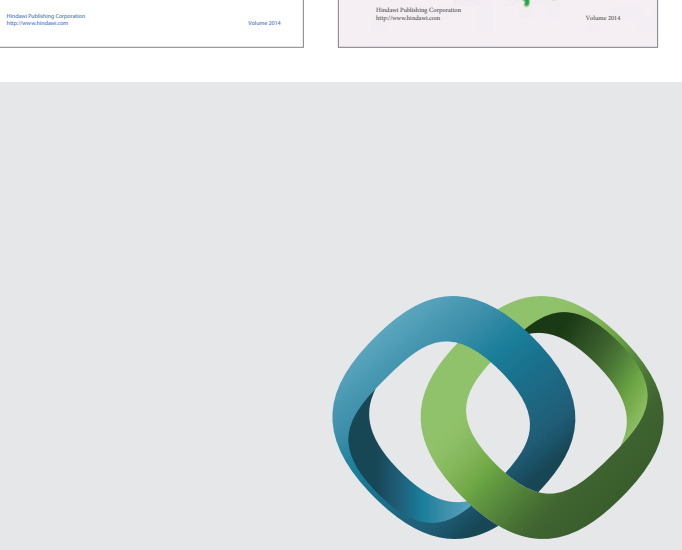

\section{Hindawi}

Submit your manuscripts at

http://www.hindawi.com
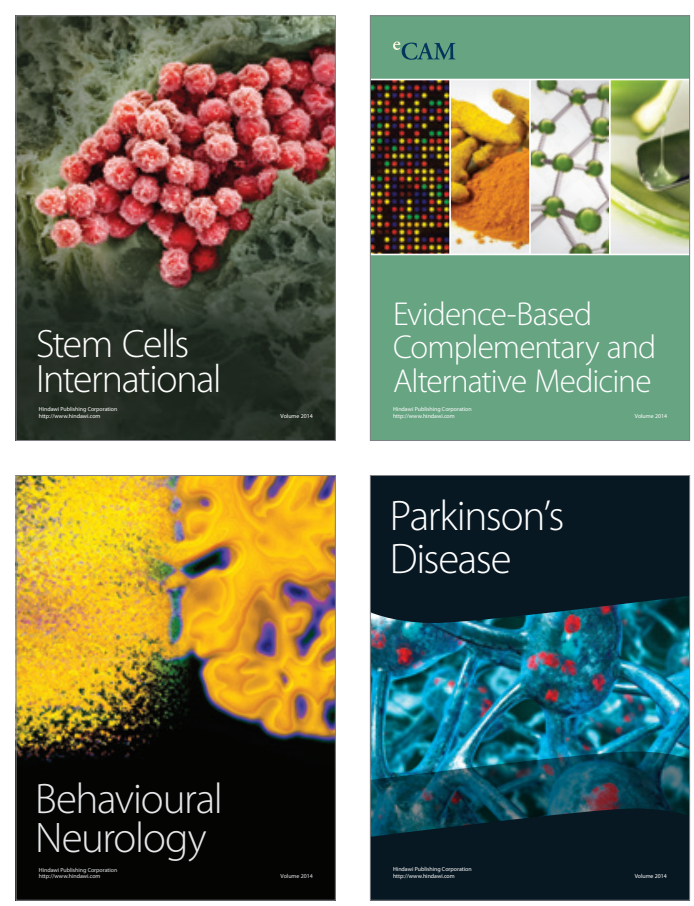

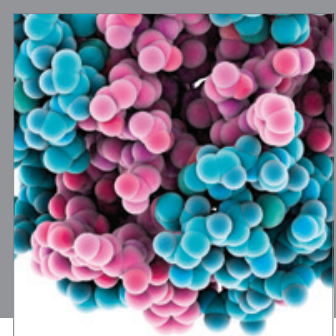

Journal of
Diabetes Research

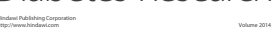

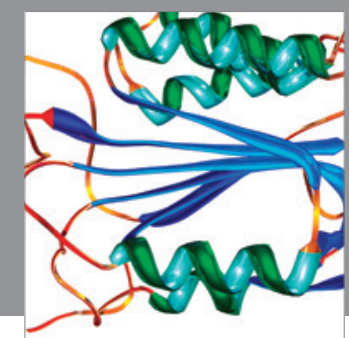

Disease Markers
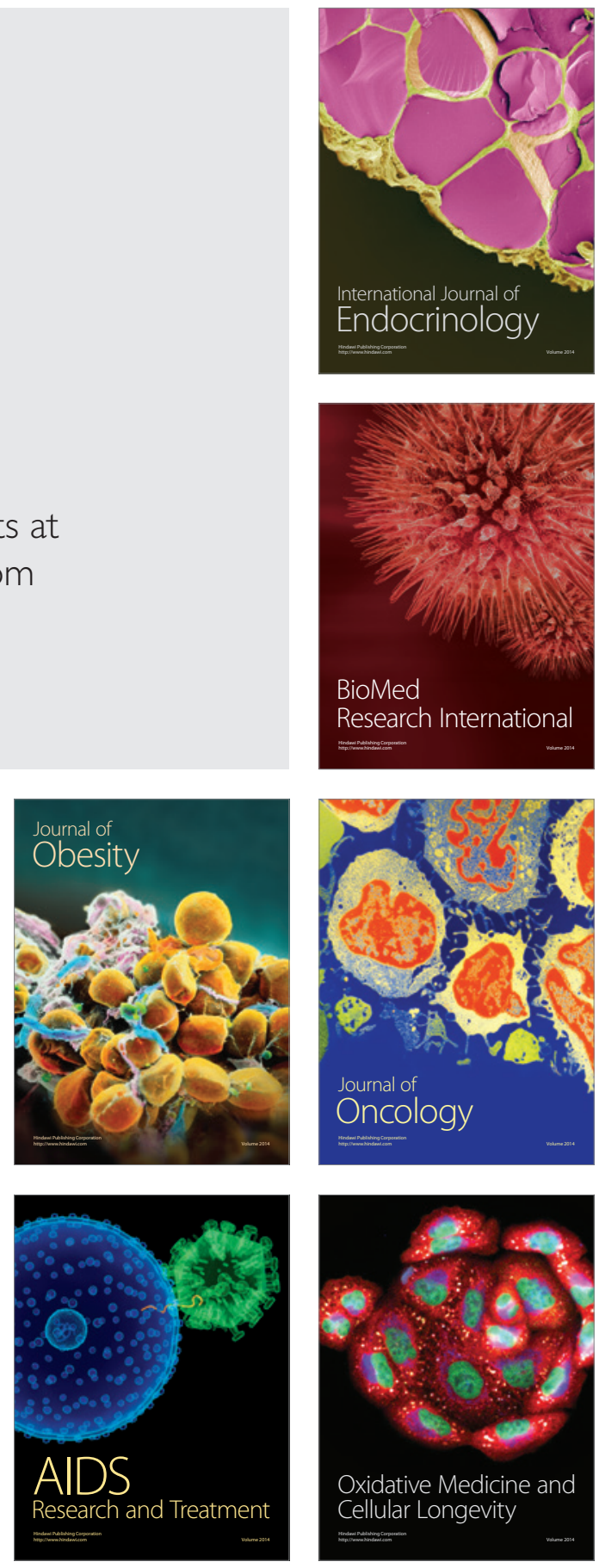